\title{
Poly- $\beta$-hydroxybutyrate production and management of cardboard industry effluent by new Bacillus sp. NA10
}

\author{
Anish Kumari Bhuwal ${ }^{1}$, Gulab Singh ${ }^{1}$, Neeraj Kumar Aggarwal ${ }^{1 *}$, Varsha Goyal ${ }^{1}$ and Anita Yadav²
}

\begin{abstract}
Background: In the present study, we aim to utilize the ecological diversity of soil for the isolation and screening for poly $\beta$-hydroxybutyrate (PHB)-accumulating bacteria and production of cost-effective bioplastic using cardboard industry effluent.

Results: A total of 120 isolates were isolated from different soil samples and a total of 62 isolates showed positive results with Nile blue A staining, a specific dye for PHB granules and 27 isolates produced PHB using cardboard industry effluent. The selected isolate NA10 was identified as Bacillus sp. NA10 by studying its morphological, biochemical, and molecular characteristics. The growth pattern for the microorganism was studied by logistic model and exactly fitted in the model. A maximum cell dry weight (CDW) of $7.8 \mathrm{~g} \mathrm{I}^{-1}$ with a PHB concentration of $5.202 \mathrm{~g} \mathrm{I}^{-1}$ was obtained when batch cultivation was conducted at $37^{\circ} \mathrm{C}$ for $72 \mathrm{~h}$, and the PHB content was up to $66.6 \%$ and productivity was $0.072 \mathrm{~g} \mathrm{I}^{-1} \mathrm{~h}^{-1}$ in $2.0 \mathrm{~L}$ fermentor. Chemical characterization of the extracted PHB was done by $\mathrm{H}_{1} \mathrm{NMR}$, Fourier transform infrared spectroscopy (FTIR), thermal gravimetric analysis (TGA), Gas chromatography-mass spectrometry (GC-MS) analysis to determine the structure, melting point, and molecular mass of the purified PHB. The polymer sheet of extracted polymer was prepared by blending the polymer with starch for packaging applications.
\end{abstract}

Conclusions: The isolate NA10 can be a good candidate for industrial production of PHB from cardboard industry waste water cost-effectively and ecofriendly.

Keywords: Polyhydroxybutyrate (PHB); Bioplastic; Cardboard industry waste water; Bacillus sp.

\section{Background}

Today, plastics have become a necessary part of contemporary life due to their durability and resistance to degradation. Worldwide production of petroleum-based synthetic polymer was approximately 270.0 million tons in 2007 [1], and these synthetic polymers are found to be recalcitrant to microbial degradation [2]. Problems related to solid waste management of these petrochemical-derived plastics pose a serious threat to global environment. Therefore, current concern about the environmental fate of polymeric materials have created much interest in the development of biodegradable plastic (bioplastic), such as starch derivatives, polylactic acid, cellulosic polymers and polyhydroxyalkanoates, which

\footnotetext{
* Correspondence: Neerajkuk26@rediffmail.com

'Department of Microbiology, Kurukshetra University, Kurukshetra, Haryana 136119, India

Full list of author information is available at the end of the article
}

plays an important role. In addition to being biodegradable, they have further advantage of being produced from renewable resources [3]. Among the various biodegradable polymer materials, polyhydroxyalkanoates (PHAs) provide a good fully degradable alternative to petrochemical plastics $[4,5]$. Polyhydroxybutyrate (PHB) was the first PHA to be discovered and is also the most widely studied and best characterized PHA. It is accumulated as a membrane enclosed inclusion in many bacteria at up to $80 \%$ of the dry cell weight and nearly $90 \%$ in recombinant E. coli [6]. In addition to the easy biodegradability and biocompatibility, it has mechanical properties that are very similar to conventional plastics like polypropylene or polyethylene and have many domestic and commercial applications such as food packing films, biodegradable carriers for medicines and insecticides, disposable cosmetic products, absorbable surgical devices and being immunologically compatible 
with human tissue can form microspheres and microcapsules [7]. Recently, PHA has been found useful as a new type of biofuel [8]. Besides all these properties and applications, wider use of PHAs is prevented mainly due to their high production cost compared with the oil-derived plastics [9]. High production cost of PHB production is mainly devoted to the expensive carbon substrates and tedious production procedures [10]. Due to the large impact of the high price of carbon sources on production costs, one of the most important approaches to reduce costs is to use wastes and by-products as raw material for the fermentation process. Novel technologies have been developed to produce PHAs from organic matters in wastewater [12-14], industrial wastes $[15,16]$, municipal waste [17], food wastes [18], and activated sludge of paper and pulp mills [19]. Hence, replacement of non-biodegradable with biodegradable plastic from organic waste can provide multiple benefits to the environment and contribute to sustainable development [20]. Therefore, organic waste from cardboard industry waste water could be a good approach for cost effective production PHA.

\section{Methods}

\section{Isolation of PHA-producing bacteria}

For the isolation of PHA-producing bacteria, various soil samples were collected from different ecological niches. The samples were stored at room temperature until analysis. In $99 \mathrm{~mL}$ sterilized water, $1 \mathrm{~g}$ of soil sample was mixed. Then, the sample was serially diluted in sterile distilled water and followed by plating on the carbon-rich nutrient agar medium (beef extract $0.3 \%$, peptone $0.5 \%$, sodium chloride $0.5 \%$, glucose $1 \%$, and agar $2 \%$ ). For the rapid detection and isolation of PHB-producing bacteria, 0.02\% alcoholic solution of Sudan black B was applied to stain bacterial colonies and the plates were kept undisturbed for $30 \mathrm{~min}$. The excess dye was then decanted, and plates were rinsed gently by adding 100\% ethanol. Colonies unable to incorporate the Sudan black B appeared white, while PHB producers appeared bluish black [21].

\section{Rapid screening for PHA-producing bacteria}

The Sudan black B-positive isolates were further screened by Nile blue A, a more specific stain for PHA by a more rapid and sensitive, viable colony method [22]. This dye at concentrations of only $0.5 \mu \mathrm{g} / \mathrm{mL}$ was directly included in carbon-rich nutrient agar medium, and growth of the cells occurred in the presence of the dye. The PHAaccumulating colonies, after Nile blue A staining, showed bright orange fluorescence on irradiation with UV light and their fluorescence intensity increased with the increase in PHA content of the bacterial cells. The isolates which showed bright orange fluorescence on irradiation with UV light after Nile blue A staining were selected as PHA accumulators. The selected PHA accumulators after Nile blue
A staining were checked for growth and PHA production in both nutrient broth (beef extract $0.3 \%$, peptone $0.5 \%$, sodium chloride $0.5 \%$ ) and cardboard industry effluent.

\section{Pretreatment of cardboard industry waste water}

Untreated cardboard industry effluent was collected from the cardboard industry, Yamunanagar (Haryana), India, and stored at $4^{\circ} \mathrm{C}$ until used for analysis. The effluent was first filtered through the muslin cloth and then through rough filter paper to remove the undesired suspended solid materials from waste water. After this pretreatment step, cardboard industry waste water was used as quantification and production medium for PHA production by selected bacterial isolate.

\section{Morphological and biochemical characterization-selected bacteria}

Microscope Stereo Olympus (America) was used to observe the morphology of bacterial colonies grown on nutrient agar. The growth characteristics such as structure, shape, color, margin, surface characteristics, elevation, cell's arrangement, and Gram staining of the bacterial colonies were observed to characterize the bacterial colonies. Various biochemical tests were performed in selected PHBproducing bacteria, namely, indole production test, methyl red and Voges-Proskauer, citrate utilization test, and $\mathrm{H}_{2} \mathrm{~S}$ production for their biochemical characterization. The fermentative utilization of various carbohydrates (xylose, mannose, maltose, sucrose, raffinose, dextrose, trehalose, fructose, glucose, ribose, lactose, rhamnose, esculin, inulin, mannitol, arabinose, sorbitol, and melibiose) were also followed for $48 \mathrm{~h}$ at $37^{\circ} \mathrm{C}$ by inoculating the selected isolate separately in the defined medium to which various sugars were added.

\section{Molecular identification \\ Colony PCR (16S rRNA gene amplification)}

Colony polymerase chain reaction (Colony PCR) of the isolate was performed according to Gen Elute ${ }^{\mathrm{Tm}}$ Bacterial genomic DNA kit (Sigma, St. Louis, MO, USA), and the colonies (approximately $1 \mathrm{~mm}$ in diameter) were picked up with a sterilized toothpick and directly transferred to the PCR tubes as DNA templates. The PCR amplification of $16 \mathrm{~S}$ rRNA was done at $94^{\circ} \mathrm{C}$ for $4 \mathrm{~min}, 94^{\circ} \mathrm{C}$ for $20 \mathrm{~s}, 52^{\circ} \mathrm{C}$ for $30 \mathrm{~s}, 72^{\circ} \mathrm{C}$ for $2 \mathrm{~min}$, and $72^{\circ} \mathrm{C}$ for $7 \mathrm{~min}$ with hold at $4^{\circ} \mathrm{C}$. The universal primer $16 \mathrm{sF}-5^{\prime}$ AGA GTT TGA TCC TGG CTC AGA $3^{\prime}$ and 16sR-5' ACG GCT ACC TTG TTA CGA CTT 3' were used.

\section{Detection of PCR products}

PCR-amplified DNA fragments were observed by agarose gel electrophoresis in $1 \% \pm$ agarose gels (FMC). Ten microliters of each amplified mixture and the molecular mass marker were subjected to agarose gel electrophoresis 
and ethidium bromide staining and tracked by $0.25 \%$ of bromophenol blue. The ampli ed DNA fragments were visualized by gel documentation box (Genie, Redmond, WA, USA).

\section{Sequencing and analysis of $16 \mathrm{~S}$ rRNA gene}

After that, the PCR product was purified by GenElute ${ }^{\mathrm{TM}}$ gel extraction kit (Sigma) method and sequencing of PCR product was done by Sanger sequencing method at $96^{\circ} \mathrm{C}$ for $1 \mathrm{~min}$, at $96^{\circ} \mathrm{C}$ for $15 \mathrm{~s}$, at $52^{\circ} \mathrm{C}$ for $30 \mathrm{~s}$, and at $60^{\circ} \mathrm{C}$ for $4 \mathrm{~min}$ for 25 cycles with a hold at $4^{\circ} \mathrm{C}$. The ABI Prism Big Dye Terminator Cycle Sequencing Ready Reaction Kit (Applied Biosystems, Foster City, CA, USA) was used for the sequencing of the PCR product. A combination of universal primers was chosen to sequence the gene sequence. Samples were run on an ABI Prism 3130×1 Genetic Analyzer (Applied Biosystems). The chromatogram was made by Chromas 2.4. software. The obtained sequence was subjected to search for closest possible species by BLAST tools and distance matrix tree tool available at National Centre for Biotechnology Information (NCBI). Phylogenetic tree was constructed by MEGA5.2 phylogenetic tree analysis software.

\section{Optimization of various growth parameters for PHB production in shake flask culture}

The optimization for maximum PHA production by selected isolate was carried in 250-ml Erlenmeyer flask using preprocessed cardboard industry waste water as production medium at $100 \mathrm{rpm}$. Several cultural parameters were evaluated to determine their effect on biomass and PHB production using cardboard industry waste water. The optimized value for each parameter was selected and kept constant for further experiments. Several cultural parameters like production media concentration (25\%-100\%) time of incubation (24-96 h), temperature of incubation $\left(25^{\circ} \mathrm{C}-55^{\circ} \mathrm{C}\right)$, and effect of $\mathrm{pH}(5.5-8)$ were evaluated to determine their effect on biomass accumulation and PHA production.

\section{Scale up of poly- $\beta$-hydroxybutyrate production and growth kinetics}

The production of PHAs was carried out in a 2.0-L fermenter (Minifors $\mathrm{CH}$ 4103, Switzerland) with a working volume of $1.25 \mathrm{~L}$ using the optimized parameters and production medium. Initially, the production medium (preprocessed undiluted cardboard industry waste water) was added into the fermenter, the $\mathrm{pH}$ was adjusted to 7.0, and the medium was sterilized in situ. Dissolved oxygen was maintained at $80 \%-100 \%$ air saturation; at the start of the process, $1 \%(v / v)$ of overnight culture (at log phase) was inoculated aseptically and the impeller speed was maintained at $100 \mathrm{rpm}$ and temperature at $37^{\circ} \mathrm{C}$. The $\mathrm{pH}$ was maintained at 7.0 using $1 \mathrm{~N} \mathrm{NaOH}$ and $1 \mathrm{~N}$
HCL. Antifoam (silicone oil) at a concentration of 1:10 $(v / v)$ in water was added after 36th and 54th hour.

The growth curves (DCW vs. time) were prepared to determine the start and end point of exponential phase for NA10 in batch fermentation. Various other growth parameters such as maximum specific growth rate $(\mu)$ and doubling time $\left(T_{\mathrm{d}}\right)$ were determined according to the method provided by Painter and Marr [24] and Levasseur et al. [25].

$$
\mu \mathrm{K}^{\prime}=\left(\operatorname{In} w_{t 2} / w_{t 1}\right) / t_{2}>t_{1} ; t_{2} t_{1}
$$

where $w_{\mathrm{t} 2}$ and $w_{\mathrm{t} 1}$ are the dry cell weight at the different time points $\left(t_{1}\right.$ and $\left.t_{2}\right)$, respectively.

$$
T_{\mathrm{d}}=\operatorname{In} 2 / \mu_{\mathrm{m}}
$$

where $T_{\mathrm{d}}$ is the doubling time and $\mu_{\mathrm{m}}$ is the maximum specific growth rate.

Cell dry weight (CDW) and PHB yield coefficient relative to cell dry weight $(\mathrm{Yp} / \mathrm{x}, g / g$, defined as gram $\mathrm{PHB}$ produced per gram dry cell mass produced) [26], PHB concentration $(\mathrm{g} / \mathrm{L}$, defined as $\mathrm{g}$ PHB measured in $1 \mathrm{~L}$ culture), PHB content $[\mathrm{g} / \mathrm{g}$, defined as the ratio of $\mathrm{PHB}$ concentration $(\mathrm{g} / \mathrm{L})$ to dry cell concentration $(\mathrm{g} / \mathrm{L})]$, and PHB productivity $(\mathrm{g} / \mathrm{L} / \mathrm{h})[10,11]$ were measured and calculated per definition during the fermentation process.

All experiments were performed in triplicate to check the reproducibility. The results were analyzed statistically by determining standard deviations values and performing analysis of variance (ANOVA) test.

\section{Extraction and quantitative analysis of PHB}

For extraction and quantitative analysis of $\mathrm{PHB}$, culture broth was centrifuged at 8,000 rpm for 15 min after $72 \mathrm{~h}$ of incubation at $37^{\circ} \mathrm{C}$. The pellet dissolved in $10 \mathrm{~mL}$ sodium hypochlorite was incubated at $50^{\circ} \mathrm{C}$ for $1 \mathrm{~h}$ for lyses of cells. The cell extract obtained was centrifuged at $12,000 \mathrm{rpm}$ for $30 \mathrm{~min}$ and then washed sequentially with distilled water, acetone, and absolute ethanol. After washing, the pellet was dissolved in $10 \mathrm{~mL}$ chloroform (AR grade) and incubated overnight at $50^{\circ} \mathrm{C}$ [23]. After evaporation at $50^{\circ} \mathrm{C}, 10 \mathrm{~mL}$ of sulfuric acid was added to it and placed in water bath for $10 \mathrm{~min}$ at $100^{\circ} \mathrm{C}$. This converts $\mathrm{PHB}$ into crotonic acid, which gives absorbance maximum at $235 \mathrm{~nm}[24,25]$. PHB (Sigma Aldrich) was used as standard for making standard curve.

\section{Polymer analysis}

\section{${ }^{1} \mathrm{H}$-NMR spectroscopy and FTIR analysis}

The identity of individual monomer unit was confirmed by proton nuclear magnetic resonance $\left({ }^{1} \mathrm{H}-\mathrm{NMR}\right)$ spectroscopy. ${ }^{1} \mathrm{H}-\mathrm{NMR}$ spectra were acquired by dissolving the polymer in deuterated chloroform $\left(\mathrm{CDCl}_{3}\right)$ at a concentration of $10 \mathrm{mg} / \mathrm{ml}$ and analyzed on a Bruker Avance 
II 500 spectrometer (Madison, WI, USA) at $22^{\circ} \mathrm{C}$ with $7.4 \mathrm{~ms}$ pulse width ( $30^{\circ}$ pulse angle), $1 \mathrm{~s}$ pulse repetition, $10,330 \mathrm{~Hz}$ spectral width, and 65,536 data points. Tetramethylsilane was used as an internal shift standard. FTIR analysis of the polymer sample was carried out on MB3000, ABB Fourier transform infrared (FTIR) spectrophotometer in the range 4,000 to $600 \mathrm{~cm}^{-1}$.

\section{TGA}

Thermal gravimetric analysis (TGA) was performed using a TGA instrument (Perkin Elmer, Diamond TG/DTA analyzer, USA) calibrated with indium. The temperature was ramped at a heating rate of $10^{\circ} \mathrm{C} / \mathrm{min}$ in nitrogenous environment to a temperature $\left(700^{\circ} \mathrm{C}\right)$ well above the degradation temperature of the polymers.

\section{GC-MS analysis}

For molecular analysis of purified polymer, a coupled Gas chromatography-mass spectrometry (GC-MS) was performed using a GC-MS-QP 2010 Plus model, with capillary Column-Rtx-5 MS (30 m $\times 0.25 \mathrm{~mm}$ i.d. $\times 0.25$ $\mu \mathrm{m}$ film thickness). The samples were injected $(3 \mu \mathrm{L})$ in the splitless mode, and the injection temperature was $260^{\circ} \mathrm{C}$ and column oven temperature was $100^{\circ} \mathrm{C}$. The mass spectra obtained were compared with the Nist-08 and Willey-08 mass spectral library.

\section{Results and discussion}

\section{Isolation and selection of PHA-producing bacteria}

A wide variety of bacteria are known to accumulate PHA granules intracellularly as an energy reserve material. Microbial species from over 90 genera have been reported to accumulate approximately 150 different hydroxyalkanoic acids as polyhydroxyalkanoate polyesters granules $[27,28]$. These bacteria have been reported from various environments. For the rapid detection and isolation of PHB-producing bacteria, $0.02 \%$ alcoholic solution of Sudan black B and Nile blue A, viable colony method [20] was used. The isolation of PHA-producing bacteria was done from various ecological niches. A total of 120 isolates showed black-blue coloration when stained with Sudan black B, a preliminary screening agent for lipophilic compounds, and a total of 62 isolates showed positive result with Nile blue A staining, a specific dye for the presence of PHA granules. Teeka et al. [29] used this method to screen the potential PHA-producing bacteria from soil, and Ramachandra and Abdullah [30] also observed the colonies formed on nutrient-rich medium under ultraviolet light (UV) to screen for the pink fluorescence which indicated the presence of PHA producers. Kitamura and Doi [31] first demonstrated this viable colony method on agar plates; they induced the isolates to accumulate PHA by culturing in $\mathrm{E}_{2}$ medium, containing $2 \%(w / v)$ glucose before Nile blue A staining. The PHA-accumulating colonies, after Nile blue A staining, showed bright orange fluorescence on irradiation with UV light and their fluorescence intensity increased with increase in PHA content of the bacterial cells.

\section{Production of PHB in nutrient broth and cardboard industry waste water}

The PHA-positive isolates selected after Nile blue A staining were screened in nutrient broth and best 27 producers were grown in processed cardboard industry waste water in 250-mL Erlenmeyer flasks and were employed to extract $\mathrm{PHB}$ after $72 \mathrm{~h}$ of incubation under stationary conditions of growth. The PHB from the isolates was extracted by the hypochlorite and chloroform method [21] as described earlier. The isolate NA10 showed maximum PHB production in both nutrient broth and cardboard industry waste water $(3.951 \mathrm{~g} / \mathrm{L}$ ) (Table 1) and were selected for further optimization of PHB production.

Organic matter from waste and wastewater have high biological oxygen demand (BOD) and carbon oxygen demand (COD) values and, hence, microorganisms can grow, utilizing the nutrient present in waste water and can convert them into valuable compounds and polymers. Based on this idea, many researchers reported the PHA production from various industrial waste materials. Many researchers have proposed coupling PHA production to biological wastewater treatment [32-34]. Rebah et al. [14] utilized two types of industrial wastewater (starch and slaughterhouse wastewater from a plant located around Quebec region) and a secondary sludge (Quebec municipal waste water treatment plant) for $\mathrm{PHB}$ production by cultivating fast-growing Rhizobia but the PHB production was very low up to $10 \%$. In an another study, Mockos et al. [35] reported that selectively enriched pulp mill waste activated sludge can serve as an inoculum for PHA production from methanol-rich pulp mill effluents, and the enriched cultures accumulated nearly 14\% PHA on a dry weight basis under nitrogen-limited conditions.

Cardboard industry waste water is typically rich in carbohydrates but poor in fixed nitrogen due to the high $\mathrm{C} / \mathrm{N}$ ratio. This high carbon-nitrogen ratio favors the growth of PHA-producing bacteria. This waste have high BOD and COD values $680-1,250 \mathrm{mg} / \mathrm{L}$ and 3,400-5,780 mg/L and COD/BOD ratio between 3.9-5 [36], which is suitable for microbial growth.

\section{Biochemical and molecular characterization of selected isolate}

By using Bergey's manual of determinative bacteriology [37] and by ABIS online, advanced bacterial identification software, the selected isolate was classified up to genus level using the morphological and biochemical characteristics (Tables 2 and 3) and was identified as Bacillus sp. For further characterization, almost complete $16 \mathrm{~S}$ rRNA 
Table 1 List of best PHA accumulating bacteria screened in nutrient broth and cardboard industry effluent

\begin{tabular}{lllll}
\hline Isolate & \multicolumn{2}{c}{ Nutrient broth } & \multicolumn{2}{c}{ Cardboard industry effluent } \\
\cline { 2 - 5 } & PHB (g/L) & Cell dry weight $\mathbf{( g / L )}$ & Cell dry weight (g/L) \\
\hline NA2 & $2.382 \pm 0.012$ & $6.2 \pm 0.23$ & $1.73 \pm 0.021$ & $4.4 \pm 0.12$ \\
NA10 & $3.512 \pm 0.011$ & $7.8 \pm 0.17$ & $3.951 \pm 0.024$ & $8.6 \pm 0.13$ \\
NA11 & $3.504 \pm 0.019$ & $8.8 \pm 0.13$ & $2.604 \pm 0.033$ & $8.8 \pm 0.16$ \\
NA12 & $4.15 \pm 0.014$ & $5.7 \pm 0.28$ & $3.387 \pm 0.027$ & $9.2 \pm 0.23$ \\
NA38 & $2.634 \pm 0.017$ & $8.4 \pm 0.13$ & $3.128 \pm 0.041$ & $7.3 \pm 0.17$ \\
NA46 & $2.574 \pm 0.021$ & $4.2 \pm 0.19$ & $2.822 \pm 0.02$ & $8.2 \pm 0.33$ \\
NA49 & $1.034 \pm 0.033$ & $6.8 \pm 0.21$ & $1.87 \pm 0.032$ & $4.8 \pm 0.13$ \\
NA52 & $3.342 \pm 0.014$ & $5 \pm 0.23$ & $2.373 \pm 0.036$ & $4.2 \pm 0.18$ \\
NA61 & $1.42 \pm 0.031$ & $4.4 \pm 0.11$ & $2.132 \pm 0.022$ & $5 \pm 0.21$ \\
NA67 & $1.334 \pm 0.033$ & $4.8 \pm 0.27$ & $2.121 \pm 0.017$ & $5 \pm 0.31$ \\
NA71 & $2.628 \pm 0.016$ & $7.6 \pm 0.33$ & $1.732 \pm 0.015$ & $3.6 \pm 0.42$ \\
NA97 & $3.154 \pm 0.009$ & $4.4 \pm 0.21$ & $3.132 \pm 0.028$ & $10.2 \pm 0.28$ \\
NA99 & $1.214 \pm 0.018$ & $5.4 \pm 0.17$ & $1.73 \pm 0.024$ & $4.8 \pm 0.26$ \\
AN23 & $2.152 \pm 0.032$ & $6.6 \pm 0.12$ & $2.143 \pm 0.033$ & $8.6 \pm 0.22$ \\
AN8 & $4.13 \pm 0.033$ & $3.658 \pm 0.035$ & $7.5 \pm 0.33$ \\
\hline
\end{tabular}

Growth and production of PHA in nutrient broth and preprocessed cardboard industry waste water after $72 \mathrm{~h}$ of incubation at $37^{\circ} \mathrm{C}$.

gene sequences were determined. The obtained sequences were aligned and compared with the bacterial sequences available in the GenBank database. The phylogenetic analysis (Figure 1) was done using MEGA 5.2 software by neighbor-joining tree and distance matrix-based nucleotide sequence homology which revealed that isolate NA10 is Bacillus sp. Yilmaz et al. [38] isolated 29 strains of the genus Bacillus from different soil samples which were taken from grasslands of Ankara, Turkey, and the highest PHB production and productivity percentage was found in Bacillus brevis M6 (41.67\% w/v).

\section{Growth pattern and PHB production in cardboard industry waste water}

As such, there is no report available from literature for PHB accumulation by microbial cells using cardboard industry waste water. The growth of Bacillus NA10 was recorded in different concentration of cardboard industry waste water (Figure 2), and the maximum growth was noted in undiluted $(100 \% v / v)$ cardboard industry

Table 2 Morphological characteristics of selected isolate NA10

\begin{tabular}{ll}
\hline Morphological characters & Results \\
\hline Colony color & White \\
Colony texture & Smooth \\
Gram reaction & + \\
Cell shape & Rod shaped \\
Cell arrangement & Isolated colonies \\
Spore formation & + \\
\hline
\end{tabular}

waste water after $72 \mathrm{~h}$ of incubation at $37^{\circ} \mathrm{C}$. Dilution of waste water not only affected the microbial growth but also the PHB accumulation. This may be due to the fact that with increasing dilution of waste water, the carbon and other nutrient got diluted and was not able to support microbial growth [38]. By submerged fermentation, Bacillus sp.NA10 accumulated highest PHB (3.952 g/L) from undiluted processed cardboard industry waste water in unoptimized cultural conditions. Quagliano et al. [39] studied the effect of molasses concentration on PHB by increasing the molasses concentration from $1 \%$ to $5 \%(w / v)$, and a maximum of $54 \%$ PHA was obtained with $5 \%$ molasses concentration with highest Mw $640 \mathrm{kDa}$. Pozo et al.

Table 3 Biochemical characteristics and carbohydrate tests of selected isolate NA10

\begin{tabular}{llll}
\hline Biochemical/carbohydrate test & Results & Carbohydrate test & Results \\
\hline Citrate utilization test & - & Glucose & + \\
Indole test & + & Raffinose & + \\
Methyl red test & - & Xylose & - \\
V-P Test & - & Sorbitol & - \\
$\mathrm{H}_{2}$ S production test & + & Lactose & - \\
Amylase production test & - & Mannose & - \\
Sucrose & + & Fructose & + \\
Dextrose & + & Ribose & - \\
Mannitol & + & Inulin & - \\
Trehalose & + & Esculin & - \\
D-Arabinose & - & Mellibiose & - \\
Maltose & + & Rammanose & - \\
\hline
\end{tabular}




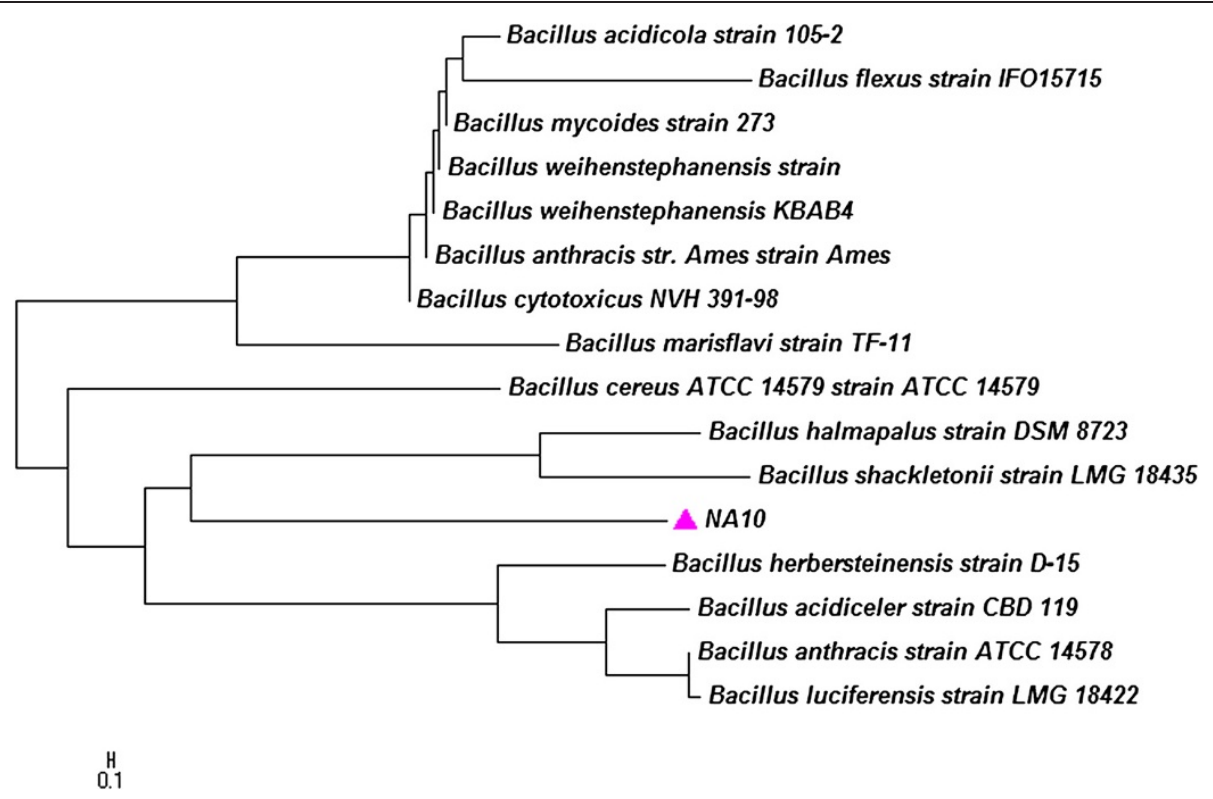

Figure 1 Neighbor-joining phylogenic tree made by MEGA 5.2 software of isolate NA10.

[40] found that $\mathrm{NH}_{4}$ medium amended with $60 \%$ alpechin showed the maximum PHA production and concluded that alpechin was tolerated by $A$. chroococcum strain $\mathrm{H} 23$ at high concentrations and that it acts as a substrate to support the growth of the microorganisms.

\section{Optimization of growth parameters}

\section{PHB production versus incubation time}

The PHB production in cardboard industry waste water was followed for $120 \mathrm{~h}$ by submerged fermentation in $250 \mathrm{~mL}$ Erlenmeyer flask at an interval of $24 \mathrm{~h}$. The production of PHB increased up to $72 \mathrm{~h}(4.456 \mathrm{~g} / \mathrm{L})$ and, thereafter, got reduced (3.26 g/L after $72 \mathrm{~h}$ ) (Figure $3 \mathrm{a})$. This reduction in $\mathrm{PHB}$ production after $72 \mathrm{~h}$ may be due to lack of micronutrients as well as increase in metabolites that might have negative effect on the PHB production. The observation was supported by Yüksekdağ et al. [41] Alcaligenes eutrophus [42] and A. vinelandii [43].

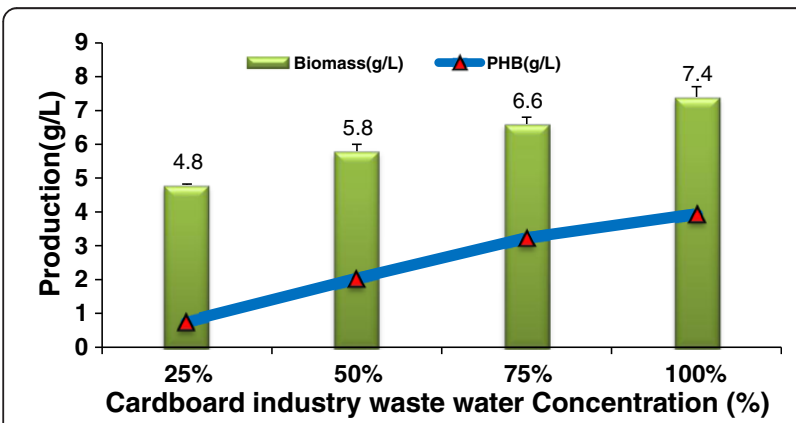

Figure 2 Growth pattern and PHB production in cardboard industry waste water.
Klüttermann et al. [44] also reported that the highest PHB level in Agrobacterium radiobacter was achieved after $96 \mathrm{~h}$. After this time, the PHB contents in fermentation broth decreased which might indicate that the bacteria used PHB as a nutrient source due to inadequate nitrogen and carbon sources in the medium.

\section{Effect of incubation temperature on PHB production}

The maximum $\mathrm{PHB}$ production of $4.274 \mathrm{~g} / \mathrm{L}$ was recorded at $35^{\circ} \mathrm{C}$ after $72 \mathrm{~h}$. The increase of temperature beyond $35^{\circ} \mathrm{C}$ has negative impact on $\mathrm{PHB}$ production (Figure $3 \mathrm{~b}$ ). This decrease in $\mathrm{PHB}$ production at high temperature is also supported by studies of Grothe et al. [10] and Yüksekdağ et al. [41]. The decrease in $\mathrm{PHB}$ production at high temperature could be due to low $\mathrm{PHB}$ polymerase enzyme activity [45]. Tamdoğan and Sidal [46] also reported that higher and lower temperatures than $30 \mathrm{C}$ lead to decrease in cell biomass and PHB synthesis by Bacillus subtilis ATCC6633.This result coincides with that represented by Aslim et al. [47], Hamieh et al. [48], who reported that optimum incubation temperature for $\mathrm{PHB}$ production by Bacillus subtilis, Bacillus pumilis and Bacillus thuringiensis was $37 \mathrm{C}$.

Effect of $\mathrm{pH}$ of the production medium on $\mathrm{PHB}$ production Typically, metabolic process was highly susceptible to even slight changes in $\mathrm{pH}$. Therefore, proper control of $\mathrm{pH}$ was critical. The experimental results showed that highest PHB content $\left(4.492 \mathrm{~g} \mathrm{~L}^{-1}\right)$ was obtained at $\mathrm{pH} 7.5$ by isolate NA10 (Figure 3c). The current observation was in agreement with Sindhu et al. [49] who observed that the maximum PHB was produced ( 0.01 to $0.5 \mathrm{~g} / \mathrm{L}$ ) at 


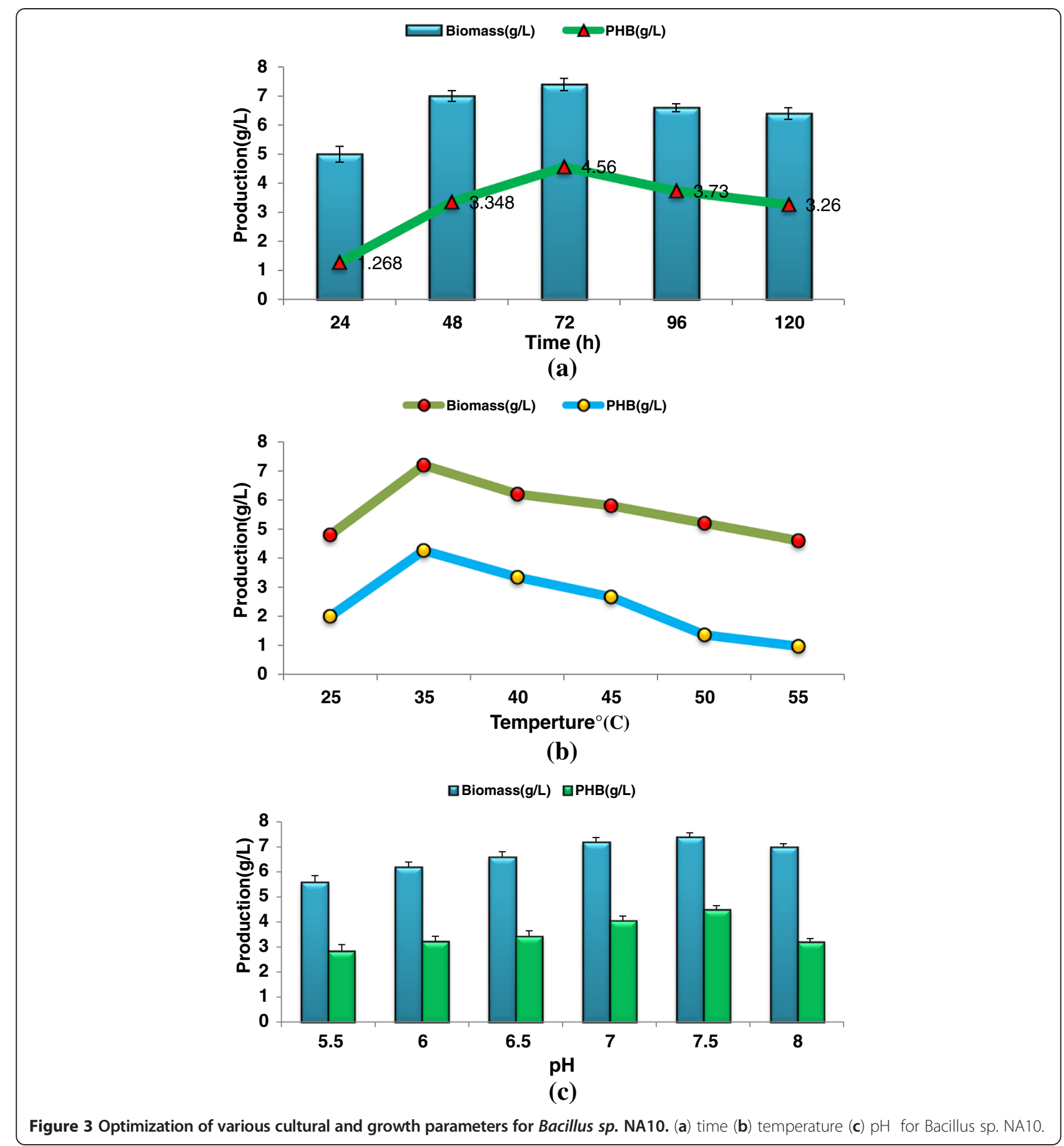

pH 7-7.5 by Bacillus sphaericus NII 0838 from crude glycerol. Flora et al. [50] revealed that the maximum PHB production $(25 \%)$ by $B$. sphaericus was at $\mathrm{pH}$ range from 6.5-7.5, and the reduction of polymer accumulation at higher $\mathrm{pH}$ values is due to the effect on the degradative enzymes of polymer breakdown, so that PHB is utilized at a rate almost equal to the rate of its synthesis. Shivakumar [51] also reported that $\mathrm{pH} 6.8$ to 8.0 was optimum for PHB production by $A$. eutrophus.

\section{Scale up study and growth kinetics}

Growth kinetics of the culture was studied in $2.0 \mathrm{~L}$ lab scale bioreactor. The profiles of PHB accumulation were analyzed in batch cultivation by growing on the cardboard industry waste water under optimized growth conditions obtained at flask level (Figure 4). The growth pattern for the microorganism was studied by logistic model and exactly fitted as presented in Figure 5. The bacteria NA10 was found to accumulate cell dry weight and specific 


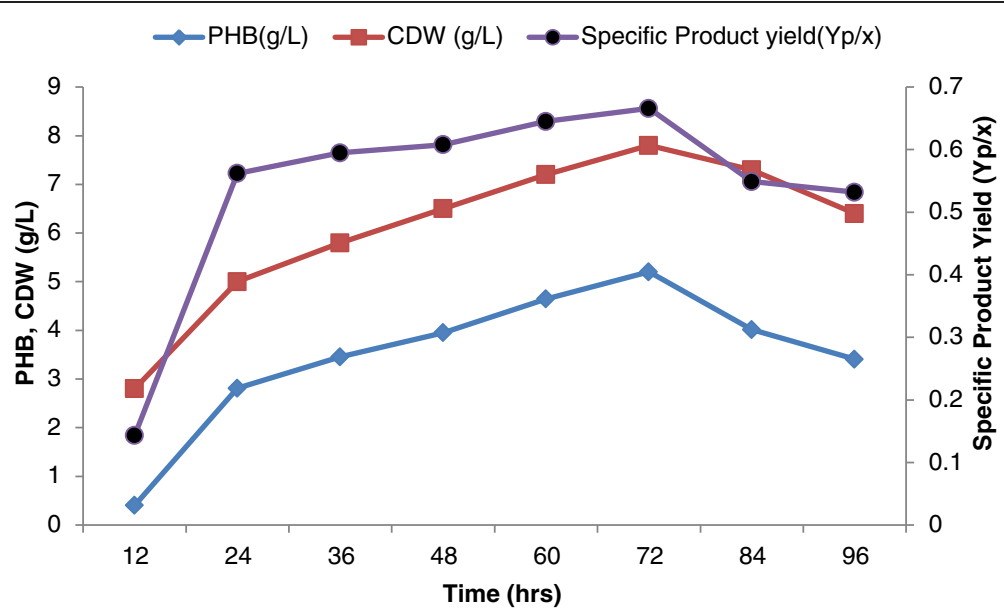

Figure 4 Cell dry weight, specific product yield (Yp/x), and PHB production by Bacillus sp. NA10 in $2.0 \mathrm{~L}$ fermenter.

product yield after the initial logarithmic growth $(24 \mathrm{~h})$ and reached a maximum $7.8 \mathrm{~g} / \mathrm{l}$ at a rate $0.028 \mathrm{~h}^{-1}$ in stationary growth phase at $72 \mathrm{~h}$. Similarly specific product yield $(\mathrm{Yp} / \mathrm{x})$ increased by about $50 \%$ from initial exponential growth to stationary phase, suggesting that cells accumulated PHB while growing and aging; hence, any strategy that prolongs the stationary phase is likely to further enhance the PHB yield per unit biomass. A maximum CDW of $7.8 \mathrm{~g} \mathrm{l}^{-1}$ with a PHB concentration of $5.202 \mathrm{~g} \mathrm{l}^{-1}$ was obtained when batch cultivation was conducted at $37^{\circ}$ $\mathrm{C}$ after $72 \mathrm{~h}$, and the PHB content was up to $66 \%$ and productivity was $0.072 \mathrm{~g} \mathrm{l}^{-1} \mathrm{~h}^{-1}$. Tanamool et al. [52] reported that maximum $0.920 \mathrm{~g} / \mathrm{l}$ of cell dry mass and $0.034 \mathrm{~g} / \mathrm{l} \mathrm{PHB}$ using sweet sorghum juice by Ralstonia eutropha with yield and productivity of $0.037 \mathrm{~g} \mathrm{PHB} / \mathrm{g}$ dry cell and $0.0019 \mathrm{~g} /(\mathrm{l} \mathrm{h})$, respectively. Similarly, El-Sayed et al. [53] found specific growth rate of $0.055 \mathrm{~h}^{-1}$ on sucrose media while a specific growth rate of $0.053 \mathrm{~h}^{-1}$ was obtained with $R$. eutropha on glucose medium.

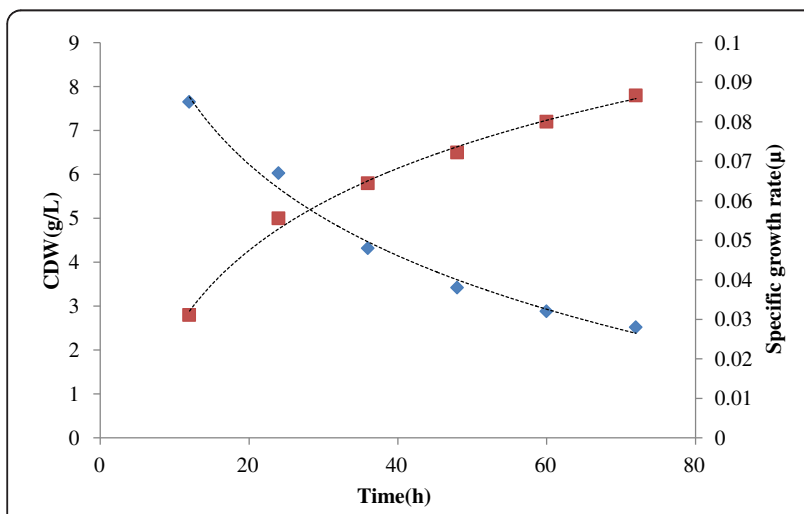

Figure 5 Logarithmic growth curve of Bacillus sp. NA10 in cardboard industry effluent.

\section{Polymer analysis}

${ }^{1} \mathrm{H}$-NMR spectroscopy

The structures of polyesters were investigated by ${ }^{1} \mathrm{H}$ NMR (Figure 6a). The ${ }^{1} \mathrm{H}$ NMR spectra of the PHAs extracted from Bacillus sp. NA10 shows a doublet at $1.26 \mathrm{ppm}$ which is attributed to the methyl group coupled to one proton, a doublet of quadruplet at $2.580 \mathrm{ppm}$ which is attributed to a methylene group adjacent to an asymmetric carbon atom bearing a single proton, and a multiplet at $5.25 \mathrm{ppm}$ characteristic of the methyne group. Two other signals are also observed, the broad one at $1.04 \mathrm{ppm}$ which is due to water, and another one at $7.27 \mathrm{ppm}$ which is attributed to chloroform. From these results, it can be concluded that Bacillus sp. NA10 cells grown with cardboard industry effluent as the carbon source produce PHA exclusively in the form of PHB.

\section{FTIR}

Polymer extracted from NA10 was used for recording IR spectra in the range 4,000 to $600 \mathrm{~cm}^{-1}$. IR spectra (Figure 6b) showed two intense absorption band at 1,720 and $1,273 \mathrm{~cm}^{-1}$ which are specific for $\mathrm{C}=\mathrm{O}$ and $\mathrm{C}-\mathrm{O}$ stretching vibrations, respectively. The absorption bands at 2,932 and 2,962 $\mathrm{cm}^{-1}$ are due to $\mathrm{C}-\mathrm{H}$ stretching vibrations of methyl and methylene groups. These prominent absorption bands confirm the structure of poly- $\beta$ hydroxybutyrate.

TGA

TGA curves were obtained in the temperature range of $30^{\circ} \mathrm{C}$ to $700^{\circ} \mathrm{C}$ for PHB. TGA results of Bacillus sp. NA10 showed that the $T_{\mathrm{m}}$ is $182.34^{\circ} \mathrm{C}$, and the enthalpy of PHA fusion is $83.62 \mathrm{~J} / \mathrm{g}$. The result showed similarity with the data obtained from standard PHB $\left(174.29^{\circ} \mathrm{C}\right.$ and $\left.86.49 \mathrm{~J} / \mathrm{g}\right)$ and from other works $[54,55]$. The PHA gave a rapid thermal degradation between $250^{\circ} \mathrm{C}$ and $290^{\circ} \mathrm{C}$ while 


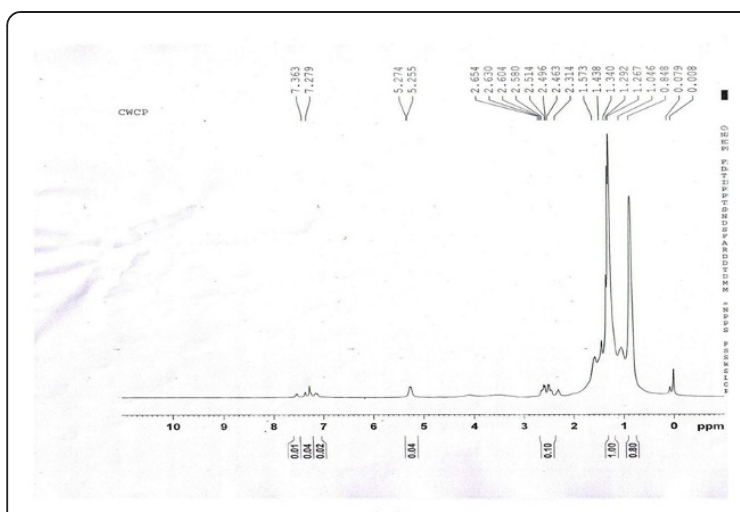

(a)

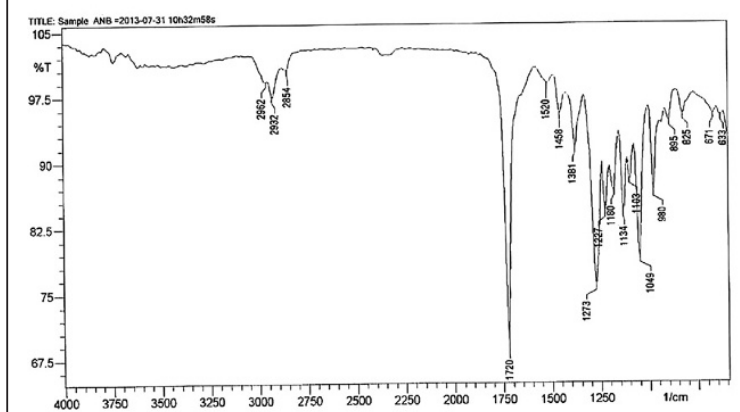

(b)

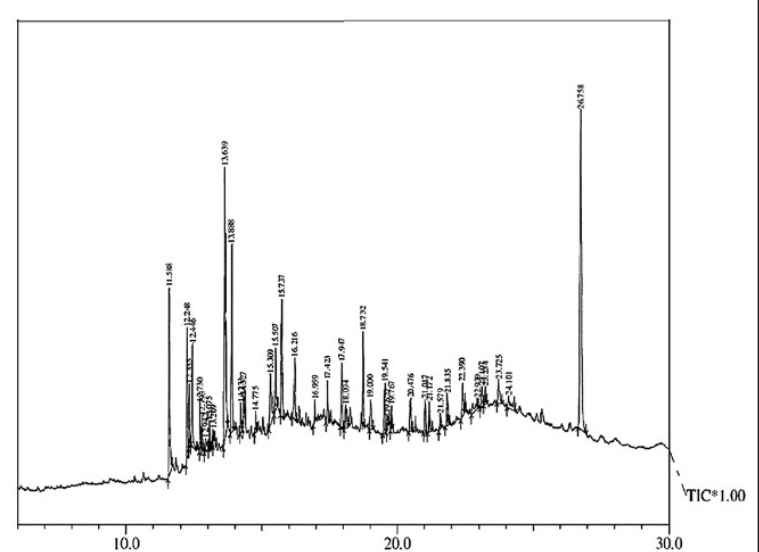

(c)

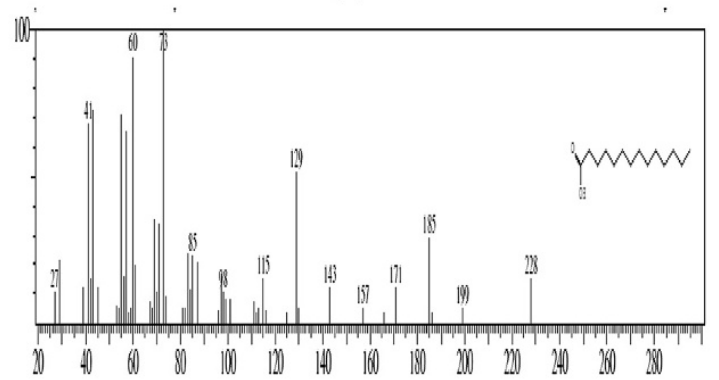

(d)

Figure 6 (a) NMR spectra (b) FTIR spectra (c, d) GC-MS of extracted polymer. the standard PHB represented at between $250^{\circ} \mathrm{C}$ and $295^{\circ} \mathrm{C}$. It is indicated that biopolymeric material obtained can possibly be further used in a large-scale processing of bioplastic [56,57].

\section{GC-MS analysis of extracted PHB}

GC-MS analysis helps in elucidating the structure of components. The key compounds of concern were identified based on their retention peak. PHA from Bacillus $s p$. NA10 cultured in processed cardboard industry waste significantly contained hexadecanoic acid, methyl ester (56\%), and tetradecanoic acid (32\%). These compounds signify that the monomer chains were of biodegradable polyester family [8]. Figure $6 c, d$ shows that a common molecular fragment of the $3 \mathrm{HB}$ ion chromatogram of the $\mathrm{PHB}$ was produced. A predominant peak corresponding to the tetramer of 3HB (hexadecanoic acid) was noted at 13.639 to $13.88 \mathrm{~min}$, respectively, in GC-purified product from Bacillus sp. NA10. The retention times and ion fragment patterns of the peaks at 11.6, 12.24, and 15.73 min were identical to those of the dimer methyl esters of $3 \mathrm{HV}$ and $3 \mathrm{HBV}$, respectively, but in low percentage up to $32 \%$ and $11 \%$, respectively. The similar results of GC-MS were observed by $\mathrm{He}$ et al. [58] with 3-hydroxydecanoate (HD or C10) $63 \%$ and 3-hydroxyoctanoate (HO or C8) $21 \%$ with other medium chain length $(\mathrm{mcl})$ monomers. From the data obtained by GC-MS, the molecular weight of PHB obtained from isolate Bacillus sp. NA10 is $242 \mathrm{kDa}$ while, the commercial PHB have a molecular weight of $275 \mathrm{kDa}$. Galego et al. [59] extracted the PHB with a molecular weight of about $177 \mathrm{kDa}$. This lowering in molecular weight is due to the presence of other polyhydroxyalkanoic acids e.g. $3 \mathrm{HV}$ and $3 \mathrm{HBV}$ up to a low percentage (32\%) with major polymer $3 \mathrm{HB}$.

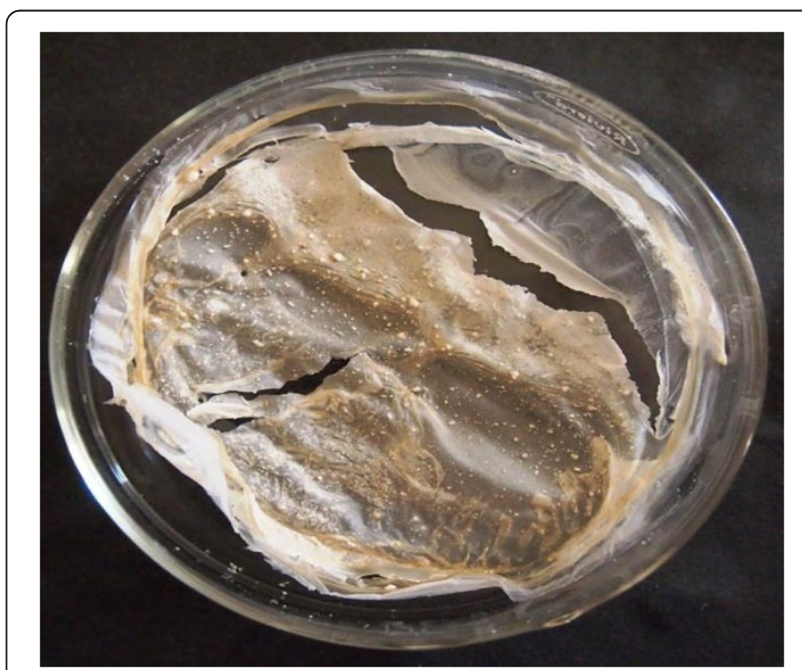

Figure 7 PHB-starch blended sheet. 


\section{Preparation of polymer blended (PHB-starch) sheet}

The PHB produced was found to be brittle and breaks easily. Blending PHB with other polymers is an economic way to improve its mechanical properties. The PHB blend sheet (Figure 7) was prepared by mixing extracted polymer with soluble starch following the conventional solvent cast technique. Starch is used for blending because it has few advantage of being biodegradable, biocompatible, cheap, and also readily available while all other biodegradable polymer such as polyethylene glycol and polylactic acid are costly. Starch-blended sheet shows better mechanical and thermal properties making it more reliable for packaging industry. As PHB and starch was not completely miscible, the blend showed insoluble particle aggregation on the surface. Identical observations were reported by Choi et al. [60] in which they prepared PHB sheet with EPB blends. The blends showed a higher thermal stability compared to PHB sheet. Parra et al. [61] reported PHB blend preparation with polyethyleneglycol (PEG) with improved properties.

\section{Conclusions}

In this study, inexpensive cardboard industry waste water was tried as a carbon source to produce PHB. Different bacterial strains were isolated from soil and screened for polyhydroxybutyrate production using cardboard manufacturing industry waste water as a carbon source. The bacterial isolate Bacillus sp. NA10 can be regarded as potential strain for conversion of cardboard industry waste water into PHB. The selected isolate efficiently utilized cardboard industry waste water as sole carbon source for growth and PHB biosynthesis, accumulating PHB up to $66.6 \%$ of the cell dry mass with $0.072 \mathrm{~g} \mathrm{l}^{-1} \mathrm{~h}^{-1}$ productivity. Currently, this bacterial strain is further studied to increase the productivity of PHB by studying the effect of various carbon and nitrogen supplementation in cardboard industry waste water.

\section{Competing interests}

The authors declare that they have no competing interests.

\section{Authors' contributions}

AKB carried out all the experimental work such as isolation, screening, fermentation studies, chemical, and statistical analysis and drafted the manuscript. GS (Gulab Singh) collected the substrate and helped in fermentor running and chemical and statistical analysis. NKA guided all the research work and participated in the design of the study. VG and AY helped in isolation and screening and provided the moral support in the whole study. All authors read and approved the final manuscript.

\section{Acknowledgements}

The authors express their sincere gratitude to the Rana Cardboard industry, Yamuna Nagar, for providing the untreated waste water. The authors are very thankful to the Department of Chemistry, Kurukshetra University, Kurukshetra, for providing the necessary facilities for NMR, FTIR, and TGA analysis of the polymer.

\section{Author details}

'Department of Microbiology, Kurukshetra University, Kurukshetra, Haryana 136119, India. ²Department of Biotechnology, Kurukshetra University, Kurukshetra 136119, India.

Received: 11 April 2014 Accepted: 30 June 2014

Published: 31 July 2014

\section{References}

1. Lazarevic D, Aoustin E, Buclet N, Brandt N (2010) Plastic waste management in the context of a European recycling society: comparing results and uncertainties in a life cycle perspective. Resour Conserv Recycling vol 55:246-259

2. Flechter A (1993) Plastics from bacteria and for bacteria: PHA as natural, biodegradable polyesters. Springer, New York, pp 77-93

3. Nath A, Dixit M, Bandiya A (2008) Enhanced PHB production and scale up studies using cheese whey in fed batch culture of Methylobacterium sp. ZP 24. Bioresource Technol 99:5749-5755

4. Anderson AJ, Dawes EA (1990) Occurrence, metabolism, metabolic role, and industrial uses of bacterial polyhydroxyalkanoates. Microbiol Rev 54:450-472

5. Yu J, Stahl H (2008) Microbial utilization and biopolyester synthesis of bagasse hydrolysates. Bioresource Technol 99:8042-8048

6. Lee IY, Chang HN, Park YH (1995) A simple method for recovery of microbial poly-3-hydroxybutyrate by alkaline solution treatment. J Microbiol Biotechnol 5(4):238-240

7. Gao X, Chen JC, Wu Q, Chen GQ (2011) Polyhydroxyalkanoates as a source of chemicals, polymers and biofuels. Curr Opin Biotechnol 22:768-774

8. Choi J, Lee SY (1997) Process analysis and economic evaluation for poly (3-hydroxybutyrate) production by fermentation. Bioprocess Eng 17:335-342

9. Yamane T, Chen XF, Ueda S (1996) Growth associated production of poly(3-hydroxyvalerate) from n-pentanol by a methylotrophic bacterium, Paracoccus denitificans. Appl Environ Microbiol 62:380-384

10. Grothe E, Moo-Young M, Chisti Y (1999) Fermentation optimization for the production of poly (ß-hydroxybutyric acid) microbial thermoplastic. Enzyme Microb Technol 25:132-141

11. Wen Q, Chen Z, Tian T, Chen W (2010) Effects of phosphorus and nitrogen limitation on PHA production in activated sludge. J Environ Scien 22 (10):1602-1607

12. Ceyhan N, Ozdemir G (2011) Polyhydroxybutyrate (PHB) production from domestic wastewater using Enterobacter aerogenes 12Bi strain. Afr J Microbiol Res 5(6):690-702

13. Wong HH, Lee SY (1998) Poly-(3-hydroxybutyrate) production from whey by high- density cultivation of recombinant Escherichia coli. Appl Microbiol Biotechnol 50:30-33

14. Rebah FB, Prévost D, Tyagi RD, Belbahri L (2009) Poly- $\beta$-hydroxybutyrate production by fast-growing Rhizobia cultivated in sludge and in industrial wastewater. Appl Biochem Biotech 158(1):155-163

15. Reddy VST, Thirumala M, Mahmood KS (2009) Production of P HB and P (3HB-co-3HV) biopolymers of Bacillus megaterium strain OU303A isolated from municipal sewage sludge. W J Microbiol Biotechnol 25:391-397

16. Koller MB, C hiellini E, Fernandes EG, Horvat P, K utschera C, Hesse P, Braunegg G (2008) Polyhydroxyalkanoate production from whey by Pseudomonas hydrogenovora. Bioresour Technol 99(11):4854-4863

17. Bengtsson S, Werker A, Welander T (2008) Production of polyhydroxyalkanoates by glycogen accumulating organisms treating a paper mill wastewater. Water Scien Technol 58:323-330

18. Du G, Yu J (2002) Green technology for conversion of food scraps to biodegradable thermoplastic polyhydroxyalkanoates. Environ Sci Technol 36:5511-5516

19. Juan ML, Gonzalez LW, Walker GC (1998) A novel screening method for isolating exopolysaccharide-deficient mutants. Appl Environ Microbiol 64:4600-4602

20. Spiekermann P, Rehm BH, Kalscheuer R, Baumeister D, Steinbüchel A (1999) A sensitive, viable-colony staining method using Nile red for direct screening of bacteria that accumulate polyhydroxyalkanoic acids and other lipid storage compounds. Arch Microbiol 171(2):73-80

21. Singh G, Mittal A, Kumari A, Goel V, Aggarwal NK, Yadav A (2011) Optimization of poly- $\beta$-hydroxybutyrate production from Bacillus species. Eur J Biol Scien 3(4):112-116

22. Law J, Slepecky RA (1961) Assay of poly-hydroxybutyric acid. J Bacteriol 82:52-55 
23. Lee YU, Yoo YJ (1991). Kinetics for the growth of Alcaligenes eutrophus and the biosynthesis of poly- $\beta$-hydoxybutyrate. Korean J Appl. Microbiol. Biotechnol 19:186-92

24. Painter PR, Marr AG (1963) Mathematics of microbial populations. Ann Rev Microbiol 22:219-221

25. Levasseur M, Thompson PA, Harrison Paul J (1993) Physiological acclimation of marine phytoplankton to different nitrogen sources. J Phycol 29(5):587-595

26. Wang F, Lee SY (1997) Poly(3-hydroxybutyrate) production with high productivity and high polymer content by a fed-batch culture of Alcaligenes latus under nitrogen limitation. Appl Environ Microbiol 63(9):3703-3706

27. Du G, Yu J, Chen J, Lun S (2001) Continuous production of poly-3hydroxybutyrate by Ralstonia eutropha in a two stage culture system. J Biotechnol 88:59-65

28. Steinbüchel A (2001) Perspectives for biotechnological production and utilization of biopolymers: metabolic engineering of polyhydroxyalkanoats biosynthesis pathways as a successful example. Macromol Bioscien 1:1-24

29. Teeka J, Cheng I, Xuehang T, Alissara R, Takaya H, Koichi Y, Masahiko S (2010) Screening of PHA-producing bacteria using biodiesel-derived waste glycerol as a sole carbon source. J Water Environ Technol 8:371-381

30. Ramachandran H, Abdullah AA (2010) Isolation of PHA-producing bacteria from Malaysian Environment. Proceedings of the 7th IMT-GT UNINET and The 3rd International PSUUNS Conferences on Bioscience 178-179

31. Kitamura S, Doi Y (1994) Staining method of poly (3-hydroxyalkanoic acid) producing bacteria by Nile Blue. Biotechnol Tech 8:345-350

32. Salehizadeh H, Van Loosdrecht MCM (2004) Production of polyhydroxyalkanoates by mixed culture: recent trends and biotechnological importance. Biotechnol Adv 22:261-279

33. Dias JM, Lemos PC, Serafim LS, Oliveira EC, Albuquerque M, Ramos M, Oliveira R, Reis MA (2006) Recent advances in polyhydroxyalkanoate production by mixed aerobic cultures: from the substrate to the final product. Macromol Biosci 6:885-906

34. Ganzeveld KJ, Van Hagen A, Van Agteren MH, Koning DW, Uiterkamp AMJS (1999) Upgrading of organic waste: production of the copolymer poly-3-hydroxybutyrate-co-valerate by Ralstonia eutrophus with organic waste as sole carbon source. J C lean Prod 7:413-420

35. Mockos G R, Loge FJ, Smith WA, and Thompson DN (2008). Selective enrichment of a methanol- utilizing consortium using pulp \& paper mill waste streams. http://www.ncbi.nlm.nih.gov/pubmed/18418753" \o "Applied biochemistry and biotechnology. Appl Biochem Biotechnol 148(1-3):211-26.

36. Rao MN, Datta AK (2007) Waste water treatment. 702 Co. Pvt. Ltd, New Delhi. pp 203-208

37. Holt John G, Krieg NR, Peter S, Staley HA, Williams Satnley T, James T (2009) Bergey's manual of determinative bacteriology, 9th edn. Lippincott Williams \& Wilkins, Baltimore, United States

38. Mirac Y, Haluk S, Yavuz B (2004) Determination of poly- $\beta$-hydroxybutyrate (PHB) production by some Bacillus spp. World J Microbiol Biotechnol 21:565-566

39. Quagliano JCF, Amarilla G, Fernandes DM, Miyazaki SS (2001) Effect of simple and complex carbon sources, low temperature culture and complex carbon feeding policies on poly-3-hydroxybutyric acid (PHB) content and molecular weight (Mw) from Azotobacter chroococcum 6B. World J Microbiol Biotechnol 17:9-14

40. Pozo C, Martı'nez-Toledo MV, Rodelas B, Gonza'lez-Lo'pez J (2002) Effects of culture conditions on the production of polyhydroxyalkanoates by Azotobacter chroococcum $\mathrm{H} 23$ in media containing a high concentration of alpechín (wastewater from olive oil mills) as primary carbon source. J Biotechnol 97:125-131

41. Yüksekdağ ZN, Aslim B, Beyatli Y, Mercan N (2004) Effect of carbon and nitrogen sources and incubation times on polybeta-hydroxybutyrate (PHB) synthesis by Bacillus subtilis 25 and Bacillus megaterium 12. African J Biotechnol 3(1):63-66

42. Khanna S, Srivastava A (2005) Recent advances in microbial polyhydroxyalkanoates. Process Biochem 40:607-619

43. Page WJ, Manchak J, Rudy B (1992) Formation of poly (hydroxybutyrate-co-hydroxyvalerate) by Azotobacter vinelandii UWD. Appl Environ Microbiol 58:28-66

44. Klüttermann K, Tauchert $\mathrm{H}$, Kleber HP (2002) Synthesis of poly-beta-hydroxybutyrate by Agrobacterium radiobacter after growth on D-Carnitine. Acta Biotechnol 22:261-269
45. Singh G, Mittal A, Kumari A, Goyal V, Yadav A, Aggarwal NK (2013) Cost effective production of poly- $\beta$-hydroxybutyrate by Bacillus subtilis NG 05 using sugar industry waste water. J Polym Environ 21:441-44

46. Tamdoğan N, Sidal U (2011) Investigation of poly- $\beta$-Hydroxybutyrate (PHB) production by Bacillus subtilis ATCC 6633 under different conditions. Kafkas Univ Vet Fak Derg 17(Suppl A):173-176

47. Aslim B, Yüksekdağ ZN, Beyatli Y (2001) Determination of growth quantities of certain Bacillus species isolated from soil. Turk Electr J Biotechnol (Sp. Issue):24-30

48. Hamieh A, Olama Z, Holail H (2013) Microbial production of polyhydroxybutyrate, a biodegradable plastic using agro-industrial waste products. G Adv Res J Microbiol 2(3):054-064

49. Sindhu R, Ammu B, Parameswaran B, Deepthi SK, Ramachandran KB, Soccol CR, Pandey A (2011) Improving its thermal properties by blending with other polymers. Brazilian J Microbiol 54(4):783-794

50. Flora G, Bhatt K, Tuteja U (2010) Optimization of culture conditions for poly- $\beta$-hydroxybutyrate production from isolated Bacillus species. J Cell Tissue Res 10:2235-2242

51. Shivakumar S (2009) Optimization of process parameters for maximum poly- $\beta$-hydroxybutyrate production by Bacillus thuringiensis IAM 12077. Pol J Microbiol 58(2):149-154

52. Tanamool V, Danvirutai $P$, Thanonkeo P, Imai T, Kaewkannetra P (2009) Production of poly- $\beta$-hydroxybutyric acid (PHB) from sweet sorghum juice by Alcaligenes eutrophus TISTR 1095 and Alcaligenes latus ATCC 29714 via batch fermentation. The 3th International Conference on Fermentation Technology for Value Added Agroculture Products 1-6

53. El-Sayed AA, Abdelhady HM, Abdel Hafez AM, Khodair TA (2009) Batch production of polyhydroxybutyrate (PHB) by Ralstonia eutropha and Alcaligenes latus using bioreactor different culture strategies. J Appl Sci Res 5(5):556-564

54. Khanna S, Srivastava A (2006) Optimization of nutrient feed concentration and addition time for production of poly( $\beta$-hydroxybutyrate). Enzyme Microbiol Technol 39:1145-1151

55. Tanamool V, Imai T, Danvirutai P, Kaewkannetra P (2011) Biosynthesis of polyhydroxyalkanoate (PHA) by Hydrogenophaga sp. isolated from soil environment during batch fermentation. J Life Sci 5:1003-1012

56. Yezza A, Halasz A, Levadoux W, Hawari J (2007) Production of poly- $\beta$-hydroxybutyrate (PHB) by Alcaligenes latus from maple sap. Apply Microbiol Biotechnol 77:269-274

57. Pachekoski WM, Agnelli JAM, Belem LP (2009) Thermal, mechanical and morphological properties of poly (hydroxybutyrate) and polypropylene blends after processing. Material Res 12:159-164

58. He W, Tian W, Zhang G, Chen GQ, Zhang Z (1998) Production of novel polyhydroxyalkanoates by Pseudomonas stutzeri 1317 from glucose and soybean oil. FEMS Microbiol Lett 169:45-49

59. Galego N, Rozsa C, Sánchez R, Fung J, Vázquez A, Tomás JS (2000) Characterization and application of poly ( $\beta$-hydroxyalkanoates) family as composite biomaterials. Polym Test 19:485-492

60. Choi JY, Lee JK, You Y, Park WH (2003) Epoxidized polybutadiene as a thermal stabilizer for poly(3-hydroxybutyrate). II. Thermal stabilization of poly (3-hydroxybutyrate) by epoxidized polybutadiene. Fiber Polym 4:195-198

61. Parra D, Rosa F,D, Rezende SP, Ponce J, Lugão AB (2011) Biodegradation of irradiated poly-3-hydroxybutyrate (PHB) films blended with poly (ethyleneglycol). J Polym Environ 19:918-925

doi:10.1186/s40643-014-0009-5

Cite this article as: Bhuwal et al:: Poly- $\beta$-hydroxybutyrate production and management of cardboard industry effluent by new Bacillus $s p$. NA10. Bioresources and Bioprocessing 2014 1:9. 